\title{
Electrochemical deposition of uranium oxide in highly concentrated calcium chloride
}

\section{AUTHOR(S):}

Uehara, Akihiro; Shirai, Osamu; Fujii, Toshiyuki; Nagai, Takayuki; Yamana, Hajimu

\section{CITATION:}

Uehara, Akihiro ...[et al]. Electrochemical deposition of uranium oxide in highly

concentrated calcium chloride. Journal of Applied Electrochemistry 2012, 42(6): 455-461

\section{ISSUE DATE:}

2012-06

URL:

http://hdl.handle.net/2433/157928

\section{RIGHT:}

The final publication is available at www.springerlink.com; この論文は 出版社版でありません。引用の際には出版社版をご確認ご利用くださ $\omega_{\circ}$; This is not the published version. Please cite only the published version. 


\title{
Electrochemical Deposition of Uranium Oxide in Highly Concentrated Calcium Chloride
}

\author{
Akihiro Uehara ${ }^{\mathrm{a}^{*}}$, Osamu Shirai ${ }^{\mathrm{b}}$, Toshiyuki Fujii ${ }^{\mathrm{a}}$, \\ Takayuki Nagai ${ }^{c}$, Hajimu Yamana ${ }^{\text {a }}$
}

a Division of Nuclear Engineering Science, Research Reactor Institute, Kyoto University, Asashironishi, Kumatori, Osaka,590-0494, Japan

b Division of Applied Life Sciences, Graduate School of Agriculture, Kyoto University, Sakyo, Kyoto, 606-8502, Japan

c Nuclear Fuel Cycle Engineering Lab., Japan Atomic Energy Agency, 4-33, Muramatsu, Tokai, Naka, Ibaraki 319-1194, Japan

\begin{abstract}
The coordination circumstances and redox reactions of $\mathrm{UO}_{2}{ }^{2+}$ in the aqueous solution concentrated by calcium chloride such as $\mathrm{CaCl}_{2} \cdot 6 \mathrm{H}_{2} \mathrm{O}\left(6.9 \mathrm{M} \mathrm{CaCl}_{2}\right)$ were studied by Raman spectroscopy and electrochemical methods. The frequency of the $\mathrm{O}=\mathrm{U}=\mathrm{O}$ symmetrical stretching vibration suggested that the complex formation of $\mathrm{UO}_{2}{ }^{2+}$ with $\mathrm{Cl}^{-}$leads to the weakening of $\mathrm{U}=\mathrm{O}$ bond. In the electrochemical measurements, two step cathodic currents were observed at -0.090 and $-0.4 \mathrm{~V}$ (vs. $\mathrm{Ag} \mid \mathrm{AgCl}$ ) corresponding to the reduction of $\mathrm{UO}_{2}{ }^{2+}$ to $\mathrm{UO}_{2}{ }^{+}$and that of $\mathrm{UO}_{2}{ }^{+}$to $\mathrm{UO}_{2}$, respectively. It was found that $\mathrm{UO}_{2}{ }^{+}$formed at first cathodic current was disproportionated to form $\mathrm{UO}_{2}{ }^{2+}$ and $\mathrm{UO}_{2}$. The $\mathrm{UO}_{2}$ was identified by X-ray diffraction analysis. Electrolytic deposition of $\mathrm{UO}_{2}$
\end{abstract}


was observed in $6.9-4.7 \mathrm{M} \mathrm{CaCl}_{2}$ and in $14 \mathrm{M} \mathrm{LiCl}$. When small amount of proton i.e., $0.005 \mathrm{M}$ was coexisted in $6.9 \mathrm{M} \mathrm{CaCl}_{2}, \mathrm{UO}_{2}{ }^{2+}$ was reduced to form $\mathrm{U}^{4+}$ instead of $\mathrm{UO}_{2}$.

Keywords: Calcium chloride, Hydrate melt, Uranium oxide, Deposit, Voltammetry, Ramman spectroscopy.

* Author to whom correspondence should be addressed

E-mail: auehara@rri.kyoto-u.ac.jp (A. Uehara)

TEL: +81-724-51-2454, FAX: +81-724-51-2634 


\section{Introduction}

Pyrochemical dry reprocessing of spent nuclear fuels has been developed with the PUREX process. The pyrochemical reprocessing includes the dissolution of spent nuclear fuels in a molten salt medium and the selective recovery of actinides. In traditional, these inorganic molten salts, act as electrolytes, are composed of an eutectic of several alkali or alkaline earth chlorides, melt at temperature above $800 \mathrm{~K}[1,2]$ depending upon the composition of the chosen eutectic. Therefore, handling difficulties or significant damages of equipment and materials have been concerned. Recently, room temperature ionic liquids (RTILs) such as 1-butyl-3-methylimidazolium chloride were introduced into the dry reprocessing of the spent nuclear fuel instead of high temperature molten salts. Giridhar et al. [3] and Asanuma et al. [4] reported that uranium was recovered by the electrochemical reduction of $\mathrm{UO}_{2}{ }^{2+}$ on the cathode. However, radiolysis of ionic liquids due to the fission products should be taken into account. On the other hand, it has been also reported that the deposition of uranium oxide was formed electrochemically in very weak acid aqueous solution [5].

Calcium chloride hexahydrate, $\mathrm{CaCl}_{2} \cdot 6 \mathrm{H}_{2} \mathrm{O}$, and similar hydrates which are highly concentrated electrolytes $\left(6.9 \mathrm{M} \mathrm{CaCl}_{2}\right)$ have low melting points and can be used as solutions. The chemical properties of their hydrates are intermediate between aqueous solutions and molten salts. By considering enthalpies of dissolution [6], activity coefficients [7], vapor pressure [8] and their structural analyses $[9,10]$, it is assumed that the water molecules in $\mathrm{CaCl}_{2} \cdot 6 \mathrm{H}_{2} \mathrm{O}$ melts are strongly coordinated to calcium ion showing that this melt is a liquid with the properties of an ionic melt composed of bulky 
hydrated cations and chloride anions. According to X-ray absorption fine structure analyses, $\mathrm{U}(\mathrm{VI})$ species in $6.9 \mathrm{M} \mathrm{CaCl}_{2}$ were estimated to be $\mathrm{UO}_{2} \mathrm{Cl}_{2}\left(\mathrm{H}_{2} \mathrm{O}\right)_{2}[11]$ which was distinctly different from $\left[\mathrm{UO}_{2}\left(\mathrm{H}_{2} \mathrm{O}\right)_{5}\right]^{2+}$ in $0.1 \mathrm{M} \mathrm{HClO}_{4}$. There are a few studies of the electrochemistry for the redox of $\mathrm{UO}_{2}{ }^{2+}$ in the aqueous solution concentrated by the electrolytes [12-14]. Cohen [12] reported that the formation of $\mathrm{UO}_{2}^{+}$in the aqueous solution highly concentrated by $\mathrm{CaCl}_{2}$ and $\mathrm{LiCl}$ was identified absorption spectrophotometrically. He has also reported that uranium compounds were deposited on the cathode by electrolysis. Bansal et al. $[13,14]$ reported that $\mathrm{UO}_{2}{ }^{2+}$ was readily reduced to $\mathrm{UO}_{2}{ }^{+}$, and that was further reduced to $\mathrm{UO}_{2}$ in the calcium nitrate terahydrate, $\mathrm{Ca}\left(\mathrm{NO}_{3}\right)_{2} \cdot 4 \mathrm{H}_{2} \mathrm{O}$, melt. However, the deposited compounds could not be identified since these compounds were very oxidative.

In the present study, the coordination circumstance and the redox reaction of $\mathrm{UO}_{2}{ }^{2+}$ in the highly concentrated $\mathrm{CaCl}_{2}$ solution are investigated based on Raman spectroscopy and cyclic voltammetry. Then uranium oxide is recovered as an electro-deposit by the controlled potential electrolysis. The mechanism of the reduction of $\mathrm{UO}_{2}{ }^{2+}$ is discussed electrochemically and spectrophotometrically. Potential-controlled electrolysis was carried out in various kinds of electrolyte solutions to define the conditions for $\mathrm{UO}_{2}$ deposition.

\section{Experimental}

Calcium chloride hexahydrate, $\mathrm{CaCl}_{2} \cdot 6 \mathrm{H}_{2} \mathrm{O}$, of analytical grade (Fluka Co.) was 
used after filtration. Uranyl chloride, $\mathrm{UO}_{2} \mathrm{Cl}_{2}$ hydrate, was prepared by evaporating aqueous solution of $\mathrm{UO}_{2} \mathrm{Cl}_{2}$ and $\mathrm{HCl}$. The $\mathrm{H}_{3} \mathrm{O}^{+}$remained in the salt was less than $1 \%$, which was calculated by $\mathrm{pH}$ measurement after solid was dissolved in a certain amount of water. The concentration of uranium ion was determined based on the absorption spectroscopy [15]. A self-registering spectrophotometer V-350 (JASCO Co.) and UV-1000 (Shimadzu Co.) was used for the measurements over the wavelength from 350 to $1700 \mathrm{~nm}$. Raman spectra were obtained an excitation using the $514.5 \mathrm{~nm}$ line of $\mathrm{Ar}^{+}$ laser (NEC, GLS3280 and GLG3280). The laser power at the sample was $300 \mathrm{~mW}$. The Raman scattering was collected at $90^{\circ}$ to the incident beam. The Raman spectra were recorded by a JASCO NR-1100 spectrometer at $0.1 \mathrm{~cm}^{-1}$ interval. The scanning rate was $60 \mathrm{~cm}^{-1} \mathrm{~min}^{-1}$. One hundred scans for one sample in the range from $800-900 \mathrm{~cm}^{-1}$ were averaged to obtain the final spectrum. The measurements were performed at ambient temperature of 293 - $295 \mathrm{~K}$, and no evidence of warming was observed.

For the electrochemical measurements, a three-electrode system was used. A glassy carbon rod (Tokai Carbon Co.) of $5 \mathrm{~mm} \phi$ or platinum rod (Nilaco Co.) of $2 \mathrm{~mm}$ $\phi$ was used as a working electrode, and the silver|silver chloride $(\mathrm{Ag} \mid \mathrm{AgCl})$ electrode was used as a reference electrode. This reference electrode consists of an end-closed tube by glass filter, in which aqueous solution containing $1 \mathrm{M} \mathrm{LiCl}$ was put in with a $\mathrm{Ag}$ wire of $1 \mathrm{~mm}$ diameter coated by $\mathrm{AgCl}$. For every electrochemical experiment, the platinum mesh electrode was employed as a counter electrode. An electrochemical measurement system, Hz-5000 (Hokuto Denko Co.) was used for the cyclic voltammetry.

In order to identify the electrode reaction, controlled potential electrolysis was 
carried out. In this experimental, a platinum mesh electrode was employed as a working electrode to enhance the efficiency of the electrolysis. The counter electrode was also platinum mesh electrode, counter phase was separated by glass filter membrane from the objective phase to avoid cyclic redox reaction. After controlled potential electrolysis, absorption spectra were measured. When an electrodeposit was obtained by the electrolysis, the deposit was separated by PTFE membrane filter and washed by ethanol. The deposit was dried up under the air condition and was analyzed by X-ray diffraction method with RINT-2100 diffractometer (Rigaku Co.) using $\mathrm{Cu} \mathrm{K \alpha}$ radiation $(40 \mathrm{kV}, 40 \mathrm{~mA})$.

These measurements were carried out at $298 \mathrm{~K}$ for cyclic voltammetry and at 332 $\mathrm{K}$ for and bulk electrolysis.

\section{Results and discussion}

\subsection{Coordination of $\mathrm{UO}_{2}{ }^{2+}$ in $6.9 \mathrm{M} \mathrm{CaCl}_{2}$}

An absorption spectrum of $\mathrm{UO}_{2} \mathrm{Cl}_{2}$ in $6.9 \mathrm{M} \mathrm{CaCl}_{2}$ was shown as curve 1 in Fig. 1. The molarabsorptivity was plotted as a function of wavelength in Fig. 1. Clear four peaks were observed at 415, 428, 440 and $476 \mathrm{~nm}$. The molar absorptivity at $428 \mathrm{~nm}$ was 19.9 , which is over twice larger than that obtained in $1 \mathrm{M} \mathrm{HClO}_{4}$ as shown by curve 2 in Fig. 1 [15]. The charge transfer band was observed in the wavelength range less than $408 \mathrm{~nm}$. The absorption spectrum in $6.9 \mathrm{M} \mathrm{CaCl}_{2}$ containing $\mathrm{UO}_{2} \mathrm{Cl}_{2}$ was 
different from that in the aqueous solution containing uranyl hydrolysis or oligomer species reported by Quiles et al. [16]. The uranyl species in $6.9 \mathrm{M} \mathrm{CaCl}_{2}$ does not form hydrolysis species even though $\mathrm{H}^{+}$was not coexistence with the melt.

Curve 1 in Fig. 2 shows the Raman spectrum of uranyl perchlorate dissolved in 1 $\mathrm{M} \mathrm{HClO}_{4}$. Here, $1 \mathrm{M}$ perchlorate solution was employed as a standard media so that the equatorial sphere of uranyl ion is coordinated by five water molecules. Under this condition, the uranyl complex is presented in the unhydrolyzed form. The band at 872 $\mathrm{cm}^{-1}$ was previously assigned to be $v_{1}$ symmetrical stretching vibration of $\mathrm{U}=\mathrm{O}$ bond [17,18]. When the Raman spectrum was measured by using $6.9 \mathrm{M} \mathrm{CaCl}_{2}$ (curve 2), the $v_{1}$ shift was observed at $855.4 \mathrm{~cm}^{-1}$ which was $16.6 \mathrm{~cm}^{-1}$ lower energy than the shift obtained in $1 \mathrm{M} \mathrm{HClO}_{4}$. This indicated that the coordination of $\mathrm{Cl}^{-}$in $6.9 \mathrm{M} \mathrm{CaCl}_{2}$ affected the polarizability of $\mathrm{U}=\mathrm{O}$ bond. Coordination number of $\mathrm{Cl}^{-}$to $\mathrm{UO}_{2}{ }^{2+}$ in concentrated $\mathrm{CaCl}_{2}$ seems to be higher than that in $\mathrm{LiCl}$ at similar concentration of $\mathrm{Cl}^{-}$ [19]. On the other hand, no difference was seen in the $v_{1}$ frequency between $\mathrm{Ca}\left(\mathrm{NO}_{3}\right)_{2} \cdot 4 \mathrm{H}_{2} \mathrm{O}(7.2 \mathrm{M} \mathrm{Ca})$ and $1 \mathrm{M} \mathrm{HClO}_{4}[20]$. This suggested that the substitution of hydrated water molecule by $\mathrm{NO}_{3}{ }^{-}$ion did not change the polarizability of $\mathrm{U}=\mathrm{O}$ bond. Covalency (or electron donating ability) of $\mathrm{O}$ donors in hydrated water molecule and $\mathrm{NO}_{3}{ }^{-}$may be similar in $\mathrm{Ca}\left(\mathrm{NO}_{3}\right)_{2} \cdot 4 \mathrm{H}_{2} \mathrm{O}$.

According to EXAFS analyses, uranyl species in $6.9 \mathrm{M} \mathrm{CaCl}_{2}$ were estimated to be $\mathrm{UO}_{2} \mathrm{Cl}_{2}\left(\mathrm{H}_{2} \mathrm{O}\right)_{2}$ [11]. The similar complex was also formed in $14 \mathrm{M} \mathrm{LiCl}$ [21] but it was distinctly different from $\left[\mathrm{UO}_{2}\left(\mathrm{H}_{2} \mathrm{O}\right)_{5}\right]^{2+}$ in $0.1 \mathrm{M} \mathrm{HClO}_{4}$. Though the coordination number of $\mathrm{Cl}^{-}$determined by XAFS [21] seems to be lower than that determined by Raman spectroscopy [19], the first coordination sphere of $\mathrm{UO}_{2}{ }^{2+}$ is surrounded by a few 
numbers of $\mathrm{Cl}^{-}$in $6.9 \mathrm{M} \mathrm{CaCl}_{2}$.

3.2. Electrochemical analysis for the redox reaction of $\mathrm{UO}_{2}{ }^{2+}$ in $6.9 \mathrm{M} \mathrm{CaCl}_{2}$

Figure 3 shows the voltammograms for the redox reaction of $0.05 \mathrm{M} \mathrm{UO}_{2} \mathrm{Cl}_{2}$ in 6.9 $\mathrm{M} \mathrm{CaCl}_{2}$ by using a platinum working electrode. When the potential scanning rate, $v$, was from 0.01 to $0.5 \mathrm{~V} \mathrm{~s}^{-1}$, a cathodic peak current $\left(I_{\mathrm{c}, 1}\right)$ was observed at $-0.090 \mathrm{~V}$ (vs. $\mathrm{Ag} \mid \mathrm{AgCl})$ corresponding to the reduction of $\mathrm{UO}_{2}{ }^{2+}$ to $\mathrm{UO}_{2}{ }^{+}$as Eq. (1);

$$
\mathrm{UO}_{2}^{2+}+\mathrm{e}^{-} \rightleftarrows \mathrm{UO}_{2}^{+}
$$

The $I_{\mathrm{c}, 1}$ was proportional to the square of $v$ between 0.01 and $0.5 \mathrm{~V} \mathrm{~s}^{-1}$ and the concentration of $\mathrm{UO}_{2}{ }^{2+}$ between $5 \times 10^{-3}$ and $0.06 \mathrm{M}$. These results indicated that the $I_{\mathrm{c}, 1}$ were controlled by the diffusion of $\mathrm{UO}_{2}{ }^{2+}$. An anodic peak current $\left(I_{\mathrm{a}, 1}\right)$ was observed at $0.025 \mathrm{~V}$ (vs. $\mathrm{Ag} \mid \mathrm{AgCl}$ ) under the potential scanning rate from 0.1 to $0.5 \mathrm{~V} \mathrm{~s}^{-1}$. Mid-point potential between cathodic and anodic peaks was found to be $-0.058 \mathrm{~V}$. Assuming that the electrode reaction of the $\mathrm{UO}_{2}{ }^{2+} \mid \mathrm{UO}_{2}{ }^{+}$couple is reversible, the diffusion coefficient of $\mathrm{UO}_{2}{ }^{2+}$ at $298 \mathrm{~K}$ can be calculated to be $1.7 \times 10^{-7} \mathrm{~cm}^{2} \mathrm{~s}^{-1}$, which was more 10 times smaller than that in diluted electrolyte solutions such as $0.1 \mathrm{M} \mathrm{HClO}_{4}\left(7.3 \times 10^{-6} \mathrm{~cm}^{2}\right.$ $\mathrm{s}^{-1}$ ) [22]. On the other hand, at $v<0.1 \mathrm{~V} \mathrm{~s}^{-1}$, anodic peak potential shifted positive from 0.025 to $0.165 \mathrm{~V}$ (vs. $\mathrm{Ag} \mid \mathrm{AgCl}$ ). This shift suggests that disproportionation of $\mathrm{UO}_{2}^{+}$ occurs after the reduction of $\mathrm{UO}_{2}{ }^{2+}$ as following reaction [13]; 


$$
2 \mathrm{UO}_{2}^{+} \rightleftarrows \mathrm{UO}_{2}^{2+}+\mathrm{UO}_{2}
$$

The rate of disproportionation in $6.9 \mathrm{M} \mathrm{CaCl}_{2}$ was estimated based on $\mathrm{EC}$ reaction undergoing Eqs. (1) and (2) to be $60 \mathrm{M}^{-2} \mathrm{~s}^{-1}$ which was similar to that in $0.4 \mathrm{M} \mathrm{HClO}_{4}$ [23]. The cyclic voltammograms were recorded at more negative potential than $-0.2 \mathrm{~V}$ as shown in Fig. 4. Another cathodic current $\left(I_{\mathrm{c}, 2}\right)$ around $-0.4 \mathrm{~V}$ (vs. $\left.\mathrm{Ag} \mid \mathrm{AgCl}\right)$ was observed, scanning potential up to $-0.5 \mathrm{~V}$ (vs. $\mathrm{Ag} \mid \mathrm{AgCl}$ ) as curve 5. The $I_{\mathrm{c}, 2}$ was estimated by the reduction of $\mathrm{UO}_{2}{ }^{+}$to $\mathrm{UO}_{2}$ as following Eq. (3);

$$
\mathrm{UO}_{2}^{+}+\mathrm{e}^{-} \rightleftarrows \mathrm{UO}_{2}
$$

This reaction is observed in high temperature molten salts [24] and RTILs [4], but not in aqueous solutions containing diluted electrolytes. On the other hand, anodic peak currents shifted depended on the negative potential region swept from -0.16 to $-0.6 \mathrm{~V}$ (vs. $\mathrm{Ag} \mid \mathrm{AgCl}$ ) as curves 3 to 5. Scanning potential up to $-0.4 \mathrm{~V}$ (vs. $\mathrm{Ag} \mid \mathrm{AgCl}$ ) as curve 3, $I_{\mathrm{a}, 1}$ decreased, two anodic currents $\left(I_{\mathrm{a}, 2}\right.$ and $\left.I_{\mathrm{a}, 3}\right)$ increased at 0.24 and $0.51 \mathrm{~V}$ (vs. $\mathrm{Ag} \mid \mathrm{AgCl}$ ), respectively. When the potential was scanned to -0.5 and $-0.6 \mathrm{~V}$ (vs. $\mathrm{Ag} \mid \mathrm{AgCl})$ as curves 4 and 5 , respectively, $I_{\mathrm{a}, 2}$ and $I_{\mathrm{a}, 3}$ were kept almost constant. Taken the disproportionation reaction as Eq. (2) and the reduction of $\mathrm{UO}_{2}{ }^{+}$as Eq. (3) into account, those anodic reactions were estimated as follows;

$$
\mathrm{UO}_{2} \rightleftarrows \mathrm{UO}_{2}^{2+}+2 \mathrm{e}^{-}
$$


$\mathrm{UO}_{2} \rightleftarrows \mathrm{UO}_{2}^{+}+\mathrm{e}^{-}$

Cyclic voltammograms depended on $v$ from 0.01 to $0.5 \mathrm{~V} \mathrm{~s}^{-1}$ were observed at the potential region between -0.5 and $0.7 \mathrm{~V}$ (vs. $\mathrm{Ag} \mid \mathrm{AgCl}$ ) in Fig. 5. Cathodic and anodic peak currents depended on $v$. At $v=0.01$ and $0.02 \mathrm{~V} \mathrm{~s}^{-1}, I_{\mathrm{c}, 2}$ was not observed. However, at $v>0.05 \mathrm{~V} \mathrm{~s}^{-1}$, second cathodic current increased with an increase in $v$. These results indicated that the concentration of $\mathrm{UO}_{2}{ }^{+}$at the electrode surface decreased due to the disproportionation as Eq. (2) at $v<0.02 \mathrm{~V} \mathrm{~s}^{-1}$.

3.3. Determination of reduction reactions by potential-controlled electrolysis in $6.9 \mathrm{M}$ $\mathrm{CaCl}_{2}$

In order to identify the reaction of $I_{\mathrm{c}, 2}$ observed at $-0.4 \mathrm{~V}$ (vs. $\mathrm{Ag} \mid \mathrm{AgCl}$ ), the potential-controlled electrolysis was carried out by applying more negative potential than $-0.5 \mathrm{~V}$. the temperature of the solution phase was kept at $332 \mathrm{~K}$ to decrease the viscosity of the hydrate melt. The viscosity of the melt at $332 \mathrm{~K}$ was about twice lower than that at $298 \mathrm{~K}$. Electrode potential was kept at $-0.6 \mathrm{~V}$ (vs. $\mathrm{Ag} \mid \mathrm{AgCl}$ ), and the electrolysis was performed for about $12 \mathrm{hrs}$. After the electrolysis, the color of the solution changed from yellow to black. When the black solution was left for one day, the black compounds precipitated on the surface of the platinum mesh working electrode and on the bottom of vessel. On the other hand, the bulk solution appeared to be clear and colorless. It was found that the compound obtained in this study was not oxidized in $\mathrm{CaCl}_{2} \cdot 6 \mathrm{H}_{2} \mathrm{O}$ at least more than two weeks, and any absorption peaks 
corresponding to uranium ions such as $\mathrm{UO}_{2}{ }^{2+}$ and $\mathrm{U}^{4+}[25]$ in $\mathrm{CaCl}_{2} \cdot 6 \mathrm{H}_{2} \mathrm{O}$ were not observed. After the deposit was filtered, it was washed by ethanol and was dried up. Figure 6 shows deposit compounds. When SEM was performed, particle size of the deposition as shown in Fig. 7 (a) was smaller than that of $\mathrm{UO}_{2}$ crystal as shown in Fig. 7 (b). When the XRD analysis was carried out by using those compounds, the result of the electro-deposit and $\mathrm{UO}_{2}$ crystal were shown as curves 1 and 2, respectively, in Fig. 8. The asterisk * indicates the peak of $\mathrm{UO}_{2}$ crystal based on the database [26]. These peaks in curve 1 gave close agreement with that of the database. However, it was found that the electro-deposit was not fine crystalline form because those compounds were mainly formed by disproportionation of $\mathrm{UO}_{2}{ }^{+}$. The percent yield of the uranium oxide calculated based on the weight of the deposit was found to be more than $85 \%$. Consequently, it was found that the reaction at $I_{\mathrm{c}, 2}$ was attributable to the deposition of $\mathrm{UO}_{2}$. Electrolytic deposition was performed in concentrated $\mathrm{CaCl}_{2}$ by Cohen et al.[12], however, they did not identified the compounds because the compound obtained by centrifuge was re-oxidized. In this study, however, by filtration and washing with ethanol, it was found that the product was not oxidized at least for a week. Bansal et al. [13] reported that the reaction at the second cathodic current at $-0.4 \mathrm{~V}$ corresponded to the formation of $\mathrm{UO}_{2}$ from $\mathrm{UO}_{2}{ }^{+}$in $\mathrm{Ca}\left(\mathrm{NO}_{3}\right)_{2} \cdot 4 \mathrm{H}_{2} \mathrm{O}$ melt as Eq. (3). They observed the deposit on the electrode surface.

Assuming that the reduction proceeds based on the Eq. (2), the deposit corresponding to the formation of $\mathrm{UO}_{2}$ on $I_{\mathrm{c}, 1}$ would be observed. To confirm the process corresponding to Eq. (2), the following procedures were duplicated for 9 times; the electrolysis was carried out for an hour by applying a constant potential, the 
absorption spectrum was measured after the electrolysis. The result was shown in Fig.

9. When $-0.05 \mathrm{~V}$ was applied for $0.5 \mathrm{~h}$, the absorption peaks corresponding to $\mathrm{UO}_{2}{ }^{+}$at wide wavelength between $500-1300 \mathrm{~nm}$ and a peak at $1510 \mathrm{~nm}$ were observed [12]. The absorption peaks increased with progress of the controlled potential electrolysis, however the black deposit of $\mathrm{UO}_{2}$ was observed on the electrode surface and in the bulk solution. After the controlled potential electrolysis procedure, the absorption peak of the $\mathrm{UO}_{2}{ }^{+}$decreased. These results indicated that $\mathrm{UO}_{2}{ }^{+}$formed by the electrochemical reduction was spontaneously converted to $\mathrm{UO}_{2}{ }^{2+}$ and $\mathrm{UO}_{2}$ by disproportionation based on the Eq. (2).

\subsection{Electrolytic deposition in various kinds of electrolyte solutions}

The potential-controlled electrolysis was carried out in various kinds of electrolyte solutions to define the conditions for $\mathrm{UO}_{2}$ deposition. Dependences of the water content in $\mathrm{CaCl}_{2} \cdot \mathrm{RH}_{2} \mathrm{O}\left(\mathrm{R}=6,7,8,9,10\right.$ and 15), of which concentration of $\mathrm{CaCl}_{2}$ were 6.9, 6.2, 5.6, 5.1, 4.7, and $3.3 \mathrm{M}$, respectively, were examined. Cyclic voltammograms were recorded in each melt containing $\mathrm{UO}_{2} \mathrm{Cl}_{2}$ as shown in Fig. 10. Peak currents increased and peak potential shifted negative with an increase in the water content. This is because the viscosity of $\mathrm{CaCl}_{2}$ solutions decreases with an increase in the water content. It was found that the deposition of $\mathrm{UO}_{2}$ was attained in the concentration range from 6.9 to $4.7 \mathrm{M} \mathrm{CaCl}_{2}$ by the electrolysis experiments without argon bubbling. Since the deposit in $4.7 \mathrm{M} \mathrm{CaCl} 2$ was not stable, the compounds were re-oxidized to form $\mathrm{UO}_{2}{ }^{2+}$ less than a week. Using $3.3 \mathrm{M} \mathrm{CaCl}_{2}, \mathrm{UO}_{2}$ 
was formed only on the surface of the electrodes and re-oxidized a few hours later. Hydrolysis species such as $\mathrm{UO}_{2}(\mathrm{OH})^{+}$and $\mathrm{UO}_{2}(\mathrm{OH})_{2}$ were formed according to the results of the absorption spectra. Similar behavior has been observed in $0.01 \mathrm{M} \mathrm{HCl}$ which is weakly acidic solutions [5] though the deposit can be obtained by the electrolysis under argon gas atmosphere.

The deposition experiment in $14 \mathrm{M} \mathrm{LiCl}$ was also carried out. Here, the concentration of $\mathrm{Cl}^{-}$in $14 \mathrm{M} \mathrm{LiCl}$ was similar to that in $6.9 \mathrm{M} \mathrm{CaCl}_{2}$. The cyclic voltammogram of $\mathrm{UO}_{2} \mathrm{Cl}_{2}$ in $14 \mathrm{M} \mathrm{LiCl}$ shows similar results obtained in $6.9 \mathrm{M} \mathrm{CaCl}_{2}$. The $\mathrm{UO}_{2}$ deposit was obtained by potential-controlled electrolysis. This is because $\mathrm{UO}_{2}{ }^{2+}$ in $14 \mathrm{M} \mathrm{LiCl}$ is coordinated by $\mathrm{Cl}^{-}$instead of $\mathrm{H}_{2} \mathrm{O}$, actually the coordination number of $\mathrm{Cl}^{-}$to $\mathrm{UO}_{2}{ }^{2+}$ in $14 \mathrm{M} \mathrm{LiCl}$ is larger than that in $6.9 \mathrm{M} \mathrm{CaCl}_{2}[11]$.

The effect of $\mathrm{H}^{+}$in concentrated $\mathrm{CaCl}_{2}$ solution on the electrolysis was examined in $6.9 \mathrm{M} \mathrm{CaCl}_{2}$ and $0.025 \mathrm{M} \mathrm{UO}_{2} \mathrm{Cl}_{2}$ coexisted with $0.005 \mathrm{M} \mathrm{HCl}$. When the cyclic voltammogram was recorded, cathodic peak current was observed at $-0.09 \mathrm{~V}$ corresponding to the reduction of $\mathrm{UO}_{2}{ }^{2+}$. However, reduction products were not $\mathrm{UO}_{2}$ deposits but tetravalent cation of $\mathrm{U}, \mathrm{U}^{4+}$, resulted from absorption spectra of bulk solution. This reaction is observed in acidic aqueous solutions as Eq. (6);

$$
2 \mathrm{UO}_{2}^{+}+4 \mathrm{H}^{+} \rightleftarrows \mathrm{UO}_{2}^{2+}+\mathrm{U}^{4+}+2 \mathrm{H}_{2} \mathrm{O}
$$

The $\mathrm{UO}_{2}{ }^{+}$formed by the electroreduction of $\mathrm{UO}_{2}{ }^{2+}$ rapidly converted to $\mathrm{UO}_{2}{ }^{2+}$ and $\mathrm{U}^{4+}$ by the disproportionation based on the Eq. (4). It was known that activity coefficient of $\mathrm{H}^{+}$was over 10 in concentrated electrolyte solutions. Therefore, it was 
suggested that small amount of $\mathrm{H}^{+}$in $\mathrm{CaCl}_{2}$ hydrate melt disturbed the deposition of $\mathrm{UO}_{2}$ from formation of $\mathrm{UO}_{2} \mathrm{Cl}_{2}$ by the electrolysis.

It was found that these reactions occurring in $\mathrm{CaCl}_{2}$ melt were different from those occurring in neutral [5] aqueous solutions as Eq. (7), respectively.

$$
2 \mathrm{UO}_{2}^{+}+\mathrm{H}^{+} \rightleftarrows \mathrm{UO}_{2}(\mathrm{OH})^{+}+\mathrm{UO}^{2+}
$$

In the reduction of $\mathrm{UO}_{2}{ }^{2+}$ on a platinized platinum electrode under certain conditions $\left(274 \mathrm{~K}, \mathrm{pH}=2.5-3.0\right.$, uranium concentration $\left.1 \times 10^{-3} \mathrm{M}\right)$ up to $90 \%$ of $\mathrm{UO}_{2}{ }^{+}$could be obtained [5], then $\mathrm{UO}_{2}{ }^{+}$disproportionated with the formation of $\mathrm{UO}_{2}(\mathrm{OH})^{+}$and $\mathrm{UO}^{2+}$ as Eq. (7). According to the Eqs. (6) and (7), $\mathrm{H}^{+}$is concerned with the reduction of $\mathrm{UO}_{2}{ }^{2+}$ in these solutions. On the other hand, $\mathrm{H}_{2} \mathrm{O}$ in hydrate melts did not dissociate to form free $\mathrm{H}^{+}$because the hydration with $\mathrm{Ca}^{2+}$ was more effective than the dissociation of $\mathrm{H}_{2} \mathrm{O}$.

\section{Conclusion}

The reduction of $\mathrm{UO}_{2}{ }^{2+}$ in highly concentrated $\mathrm{CaCl}_{2}$ and $\mathrm{LiCl}$ was investigated based on cyclic voltammetry and controlled potential electrolysis. Mid-point potential for the redox of the $\mathrm{UO}_{2}{ }^{2+} \mid \mathrm{UO}_{2}{ }^{+}$couple determined to be $-0.058 \mathrm{~V}$ (vs. $\mathrm{Ag} \mid \mathrm{AgCl}$ ). The $\mathrm{UO}_{2}{ }^{+}$formed by the electroreduction of $\mathrm{UO}_{2}{ }^{2+}$ was converted spontaneously to form both $\mathrm{UO}_{2}{ }^{2+}$ and $\mathrm{UO}_{2}$ by the disproportionation of $\mathrm{UO}_{2}{ }^{+}$. It was found that $\mathrm{UO}_{2}$ deposit 
was obtained by the electrolysis in highly concentrated $\mathrm{CaCl}_{2}(>4.7 \mathrm{M})$ and $\mathrm{LiCl}$ at room temperature without nitrogen substitution, since $\mathrm{Cl}^{-}$'s coordinate equatorial sphere of $\mathrm{UO}_{2}{ }^{2+}$ resulted in avoiding the hydrolysis. However, $\mathrm{UO}_{2}{ }^{2+}$ was easily reduced to $\mathrm{U}^{4+}$ when lower concentration of $\mathrm{H}^{+}$than $\mathrm{UO}_{2}{ }^{2+}$ existed in the concentrated electrolytes.

\section{Acknowledgement}

The authors thank Prof. S. Kihara (Kumamoto Univ.) and Prof. N. Sato (Tohoku Univ.) for their fruitful discussions. This research was partly supported by Grants-in-Aid for Scientific Research (No. 19760611 and 22760672) from the Ministry of Education, Culture, Sports, Science and Technology, Japan.

\section{References}

[1] J.L. Willit, W.E. Miller, J.E. Battles, J. Nucl. Matr. 195 (1992) 229.

[2] G.R. Choppin, A. Morgenstern, J. Radioanal. Nucl. Chem. 243 (2000) 45.

[3] P. Giridhar, K.A. Venkatesan, T.G. Srinivasan, P.R. Vasudeva Rao, Electrochim. Acta 52 (2007) 3006.

[4] N. Asanuma, M. Harada, Y. Yasuike, M. Nogami, K. Suzuki, Y. Ikeda, J. Nucl. Sci. Technol. 44 (2007) 368. 
[5] W.E. Harris and I.M. Kolthoff, J. Am. Chem. Soc., 69 (1947) 446.

[6] G.C. Sinke, E.H. Mossner, J.L. Curnutt, J. Chem. Thermodynamics 17 (1985) 893.

[7] J.A. Rard, S.L. Clegg, J. Chem. Eng. Data 42 (1997) 819.

[8] G.G. Aseyev, Electrolytes: Equilibria in solutions and phase equilibria, Begell house Inc.1999.

[9] A.A. Chialvo, J.M. Simonson, J. Chem. Phys. 119 (2003) 8052.

[10] T. Yamaguchi, S. Hayashi, H. Ohtaki, Inorg. Chem., 28 (1989) 2434.

[11] A. Uehara, T. Fujii, H. Matsuura, N. Sato, H. Yamana, Y. Okamoto, OECD-NEA, 15 (2009) 197.

[12] D. Cohen, J. Inorg. Nucl. Chem. 32 (1970) 3525.

[13] N.P. Bansal, J.A. Plambeck, Electrochim. Acta, 23 (1978) 1053.

[14] N.P. Bansal, J.A. Plambeck, Can. J. Chem., 59 (1981) 1515.

[15] D.M. Gruen, R.L. McBeth, J. Inorg. Nucl. Chem. 9 (1959) 290.

[16] F. Quiles, C. Nguyen-Trung, C. Carteret, B. Humbert, Inorg. Chem., 50 (2011) 2811.

[17] L.M. Toth, G.M. Begun, J. Phys. Chem. 85 (1981) 547.

[18] M. Asano, J.A. Koningstein, Can. J. Chem. 60 (1982) 2207.

[19] C. Nguyen-Trung, G.M. Begun. and D.A. Palmer, Inorg. Chem., 31 (1992) 5280.

[20] T. Fujii, H. Yamana, H. Moriyama, J. Nucl. Sci. Technol. Suppl. 3(2002) 336.

[21] P.G. Allen, J.J. Bucher, D.K. Shuh, N.M. Edelstein, and T. Reich, Inorg. Chem., 36 (1997) 4676. 
[22] A.P. Vinogradov Ed. Analytical Chemistry of Uranium, Academy of Sciences, Moskva, 1962, p. 144.

[23] R.T. Iwamoto, J. Am. Chem. Soc., 63 (1959) 303.

[24] I. Uchida, J. Nikura, S. Toshima, J. Electroanal. Chem., 124 (1981) 165.

[25] A. Uehara, T. Fujii, T. Nagai, O. Shirai, N. Sato, H. Yamana, Recent Advances in Actinide Science, I. May, R. Alvares, N. Bryan Eds. pp. 548-550 (2006).

[26] Powder diffraction file, Inorganic phases, Inter. Ctr. Diffraction Data, 1992.

\section{Figure captions}

Fig. 1. Absorption spectra of uranium ion in $6.9 \mathrm{M} \mathrm{CaCl}_{2}$ (curve 1) and $1 \mathrm{M} \mathrm{HClO}_{4}$ (curve 2) at $298 \mathrm{~K}$.

Fig. 2. Raman spectra of uranium ion in $1 \mathrm{M} \mathrm{HClO}_{4}$ (curve 1) and $6.9 \mathrm{M} \mathrm{CaCl}_{2}$ (curve 2) at $298 \mathrm{~K}$.

Fig. 3 Cyclic voltammogram for the redox reaction of $\mathrm{UO}_{2}{ }^{2+}$ in $6.9 \mathrm{M} \mathrm{CaCl}_{2}$ at 298 $\mathrm{K}$. Concentration of $\mathrm{UO}_{2}{ }^{2+} ; 0.05 \mathrm{M}$, working electrode; platinum rod of 2 $\mathrm{mm} \phi$, potential scanning rate; from 0.005 to $0.2 \mathrm{~V} \mathrm{~s}^{-1}$.

Fig. 4 Cyclic voltammograms for the redox reaction of $\mathrm{UO}_{2}{ }^{2+}$ in $6.9 \mathrm{M} \mathrm{CaCl}_{2}$ at 
$298 \mathrm{~K}$. Concentration of $\mathrm{UO}_{2}{ }^{2+} ; 0.05 \mathrm{M}$, working electrode; platinum rod of $2 \mathrm{~mm} \phi$, potential scanning rate; $0.1 \mathrm{~V} \mathrm{~s}^{-1}$, potential scanning range; from -0.15 to $0.7 \mathrm{~V}$ (curve 1 ), from -0.3 to $0.7 \mathrm{~V}$ (curve 2 ), from -0.4 to $0.7 \mathrm{~V}$ (curve 3 ) and from -0.5 to $0.7 \mathrm{~V}$ (curve 4 ), from -0.6 to $0.7 \mathrm{~V}$ (curve 5 ), and from -0.7 to $0.7 \mathrm{~V}$ (curve 6 ), respectively.

Fig. 5 Cyclic voltammogram for the redox reaction of $\mathrm{UO}_{2}{ }^{2+}$ in $6.9 \mathrm{M} \mathrm{CaCl}_{2}$ at 298 $\mathrm{K}$. Concentration of $\mathrm{UO}_{2}{ }^{2+} ; 0.05 \mathrm{M}$, working electrode; glassy carbon rod of $5 \mathrm{~mm} \phi$, potential scanning rate; from 0.01 to $0.2 \mathrm{~V} \mathrm{~s}^{-1}$.

Fig. 6 Photo of the electrolytic deposit of uranium oxide.

Fig. 7 SEM micrograph of the electrolytic deposit of uranium (a) and $\mathrm{UO}_{2}$ powder (b).

Fig. 8 X-ray diffraction analysis of the electrolytic deposit of uranium (curve 1) and $\mathrm{UO}_{2}$ powder (curve 2). The asterisk “*” indicates the peak of $\mathrm{UO}_{2}$ crystal based on the database.

Fig. 9 Absorption spectra of $\mathrm{UO}_{2} \mathrm{Cl}_{2}$ in $6.9 \mathrm{M} \mathrm{CaCl}_{2}$ before and after electrolysis.

Fig. 10 Cyclic voltammograms for the redox of the $\mathrm{UO}_{2}{ }^{2+}$ in $6.9 \mathrm{M} \mathrm{CaCl}_{2}$ (curve 1), 6.2 $\mathrm{M}$ (curve 2), 5.6 M (curve 3), 5.1 M (curve 4), 4.7 M (curve5), and 3.3 $\mathrm{M}$ 
(curve 6), respectively. 


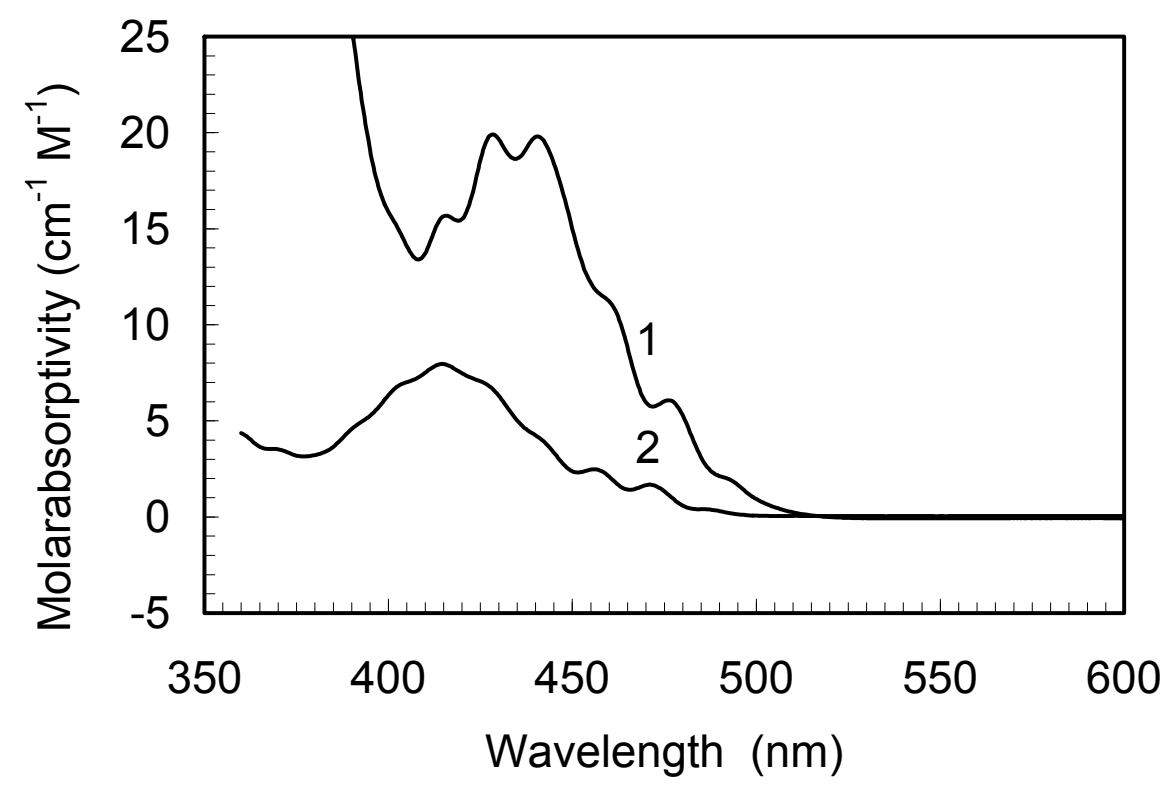

Fig. 1, Uehara, et al., 


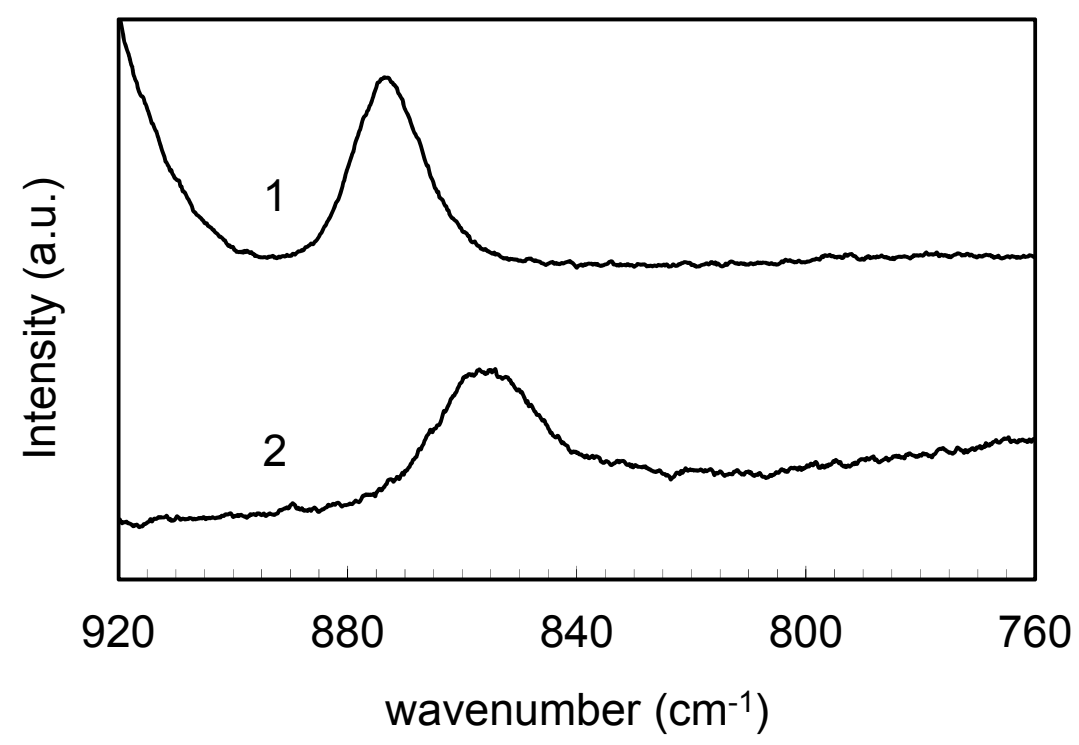

Fig. 2, Uehara, et al., 


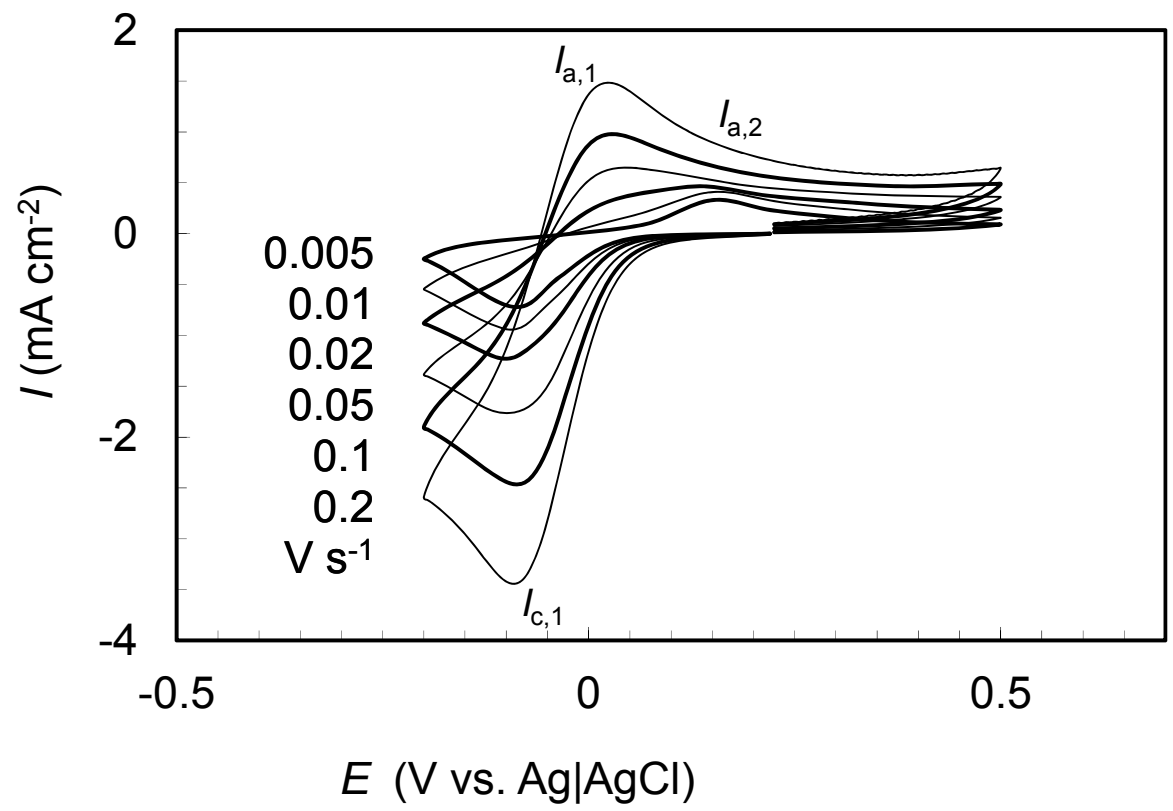

Fig. 3, Uehara, et al., 


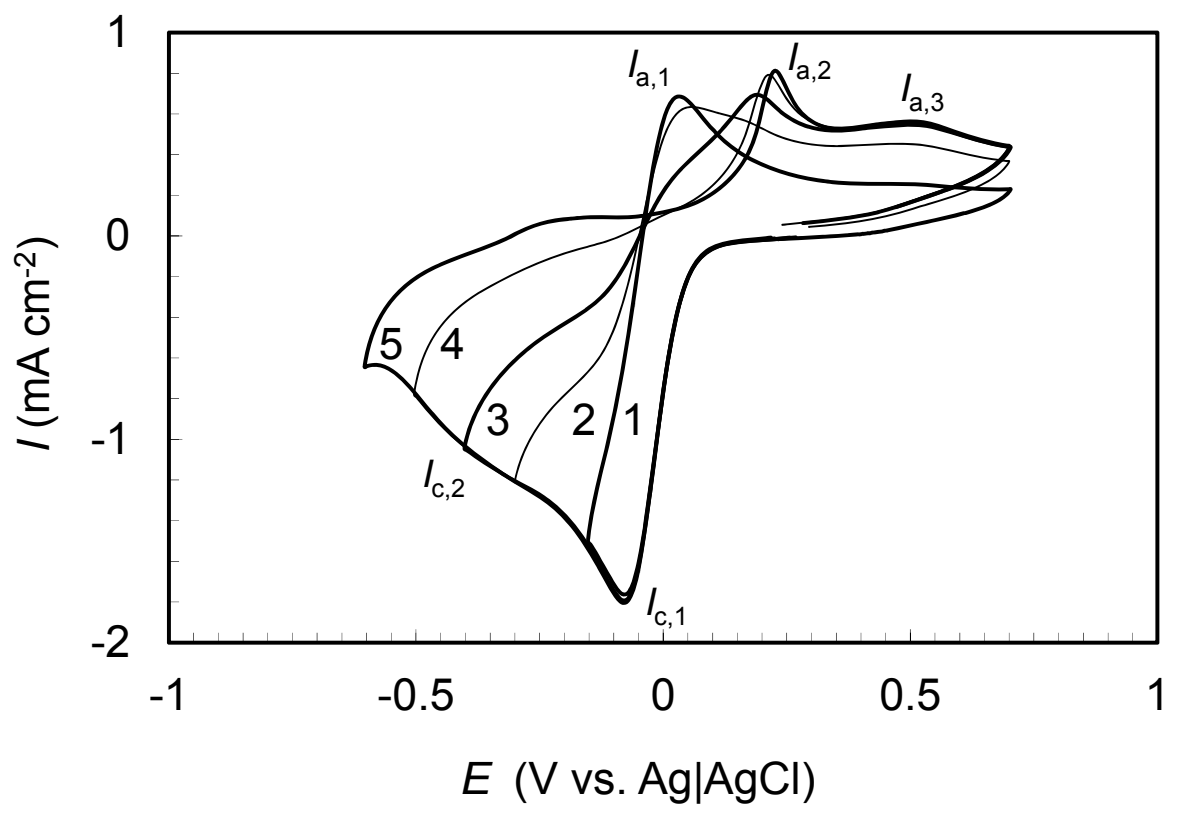

Fig. 4, Uehara, et al., 


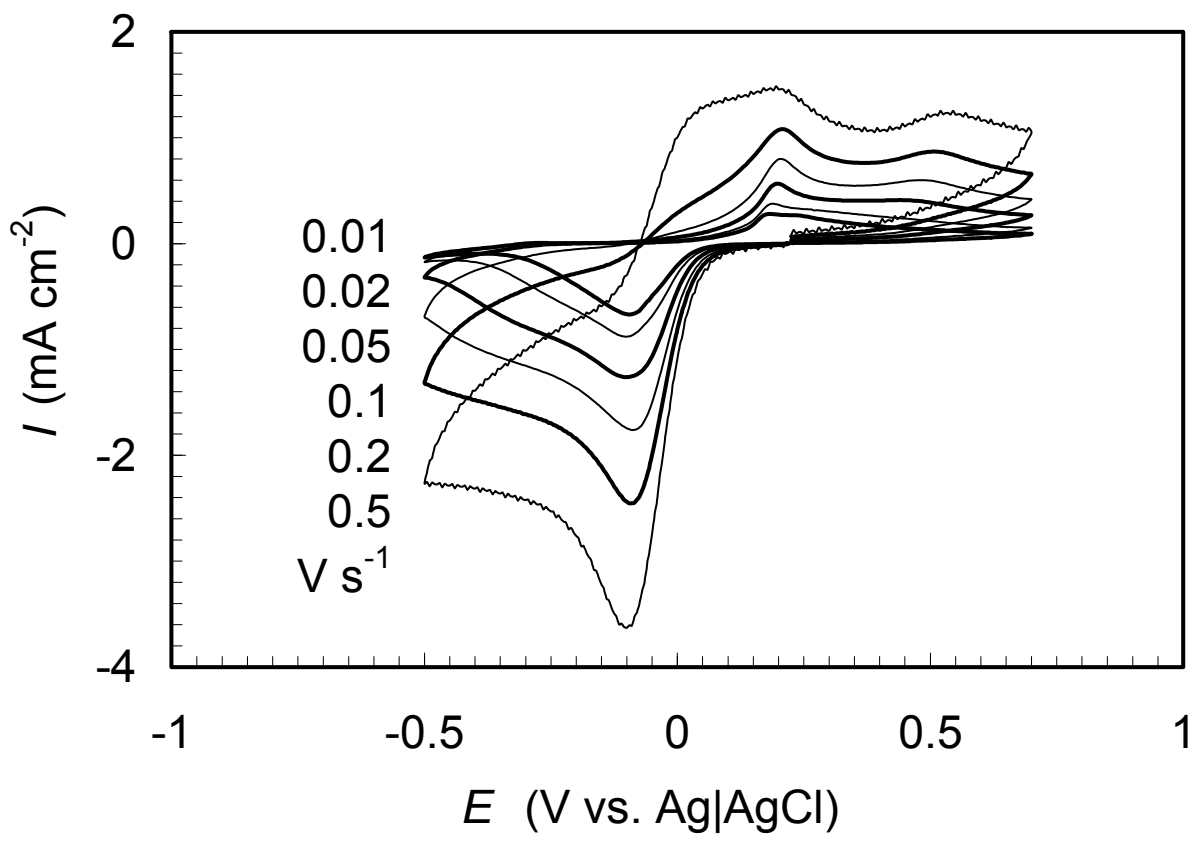

Fig. 5, Uehara, et al., 


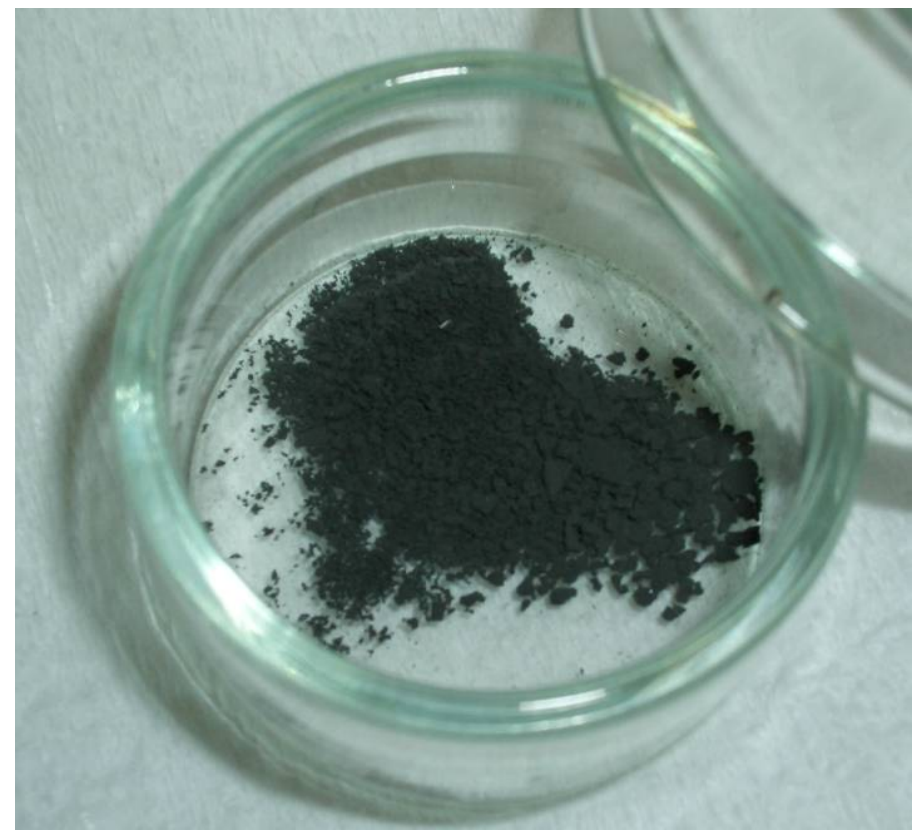

Fig. 6, Uehara, et al., 


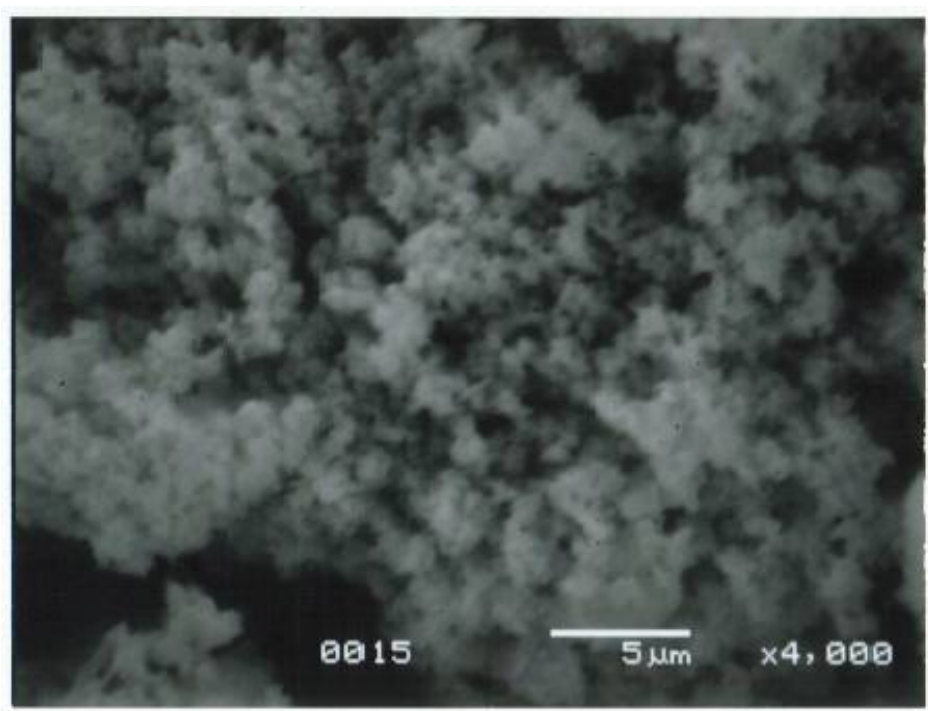

(a)

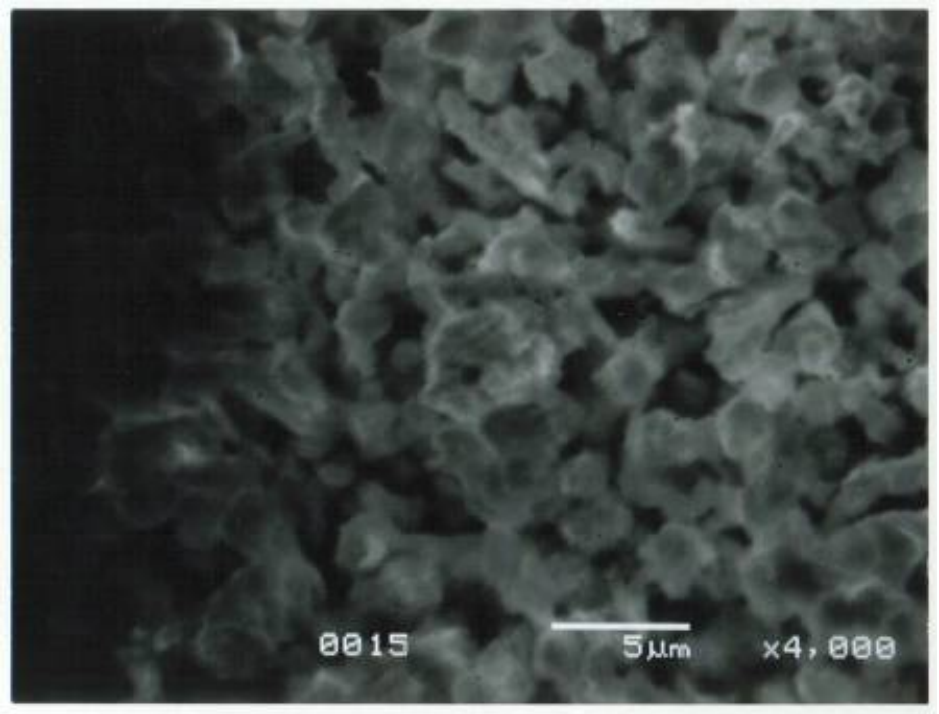

(b)

Fig. 7, Uehara, et al., 


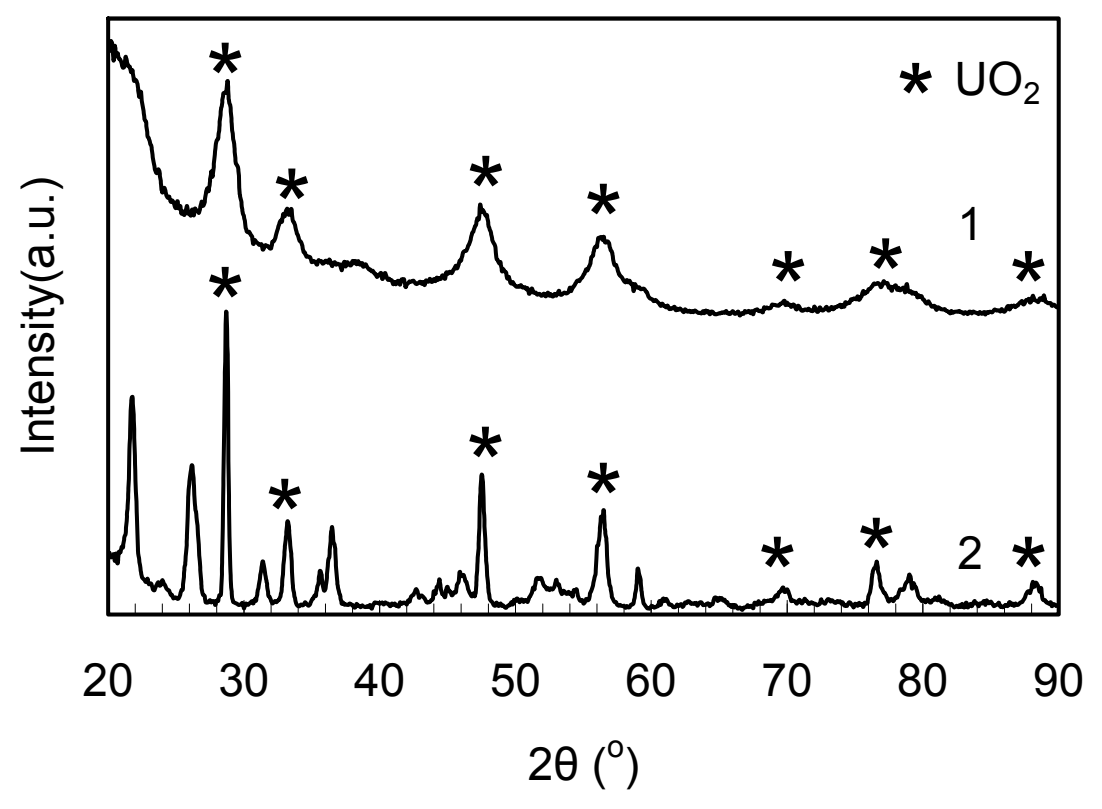

Fig. 8, Uehara, et al., 

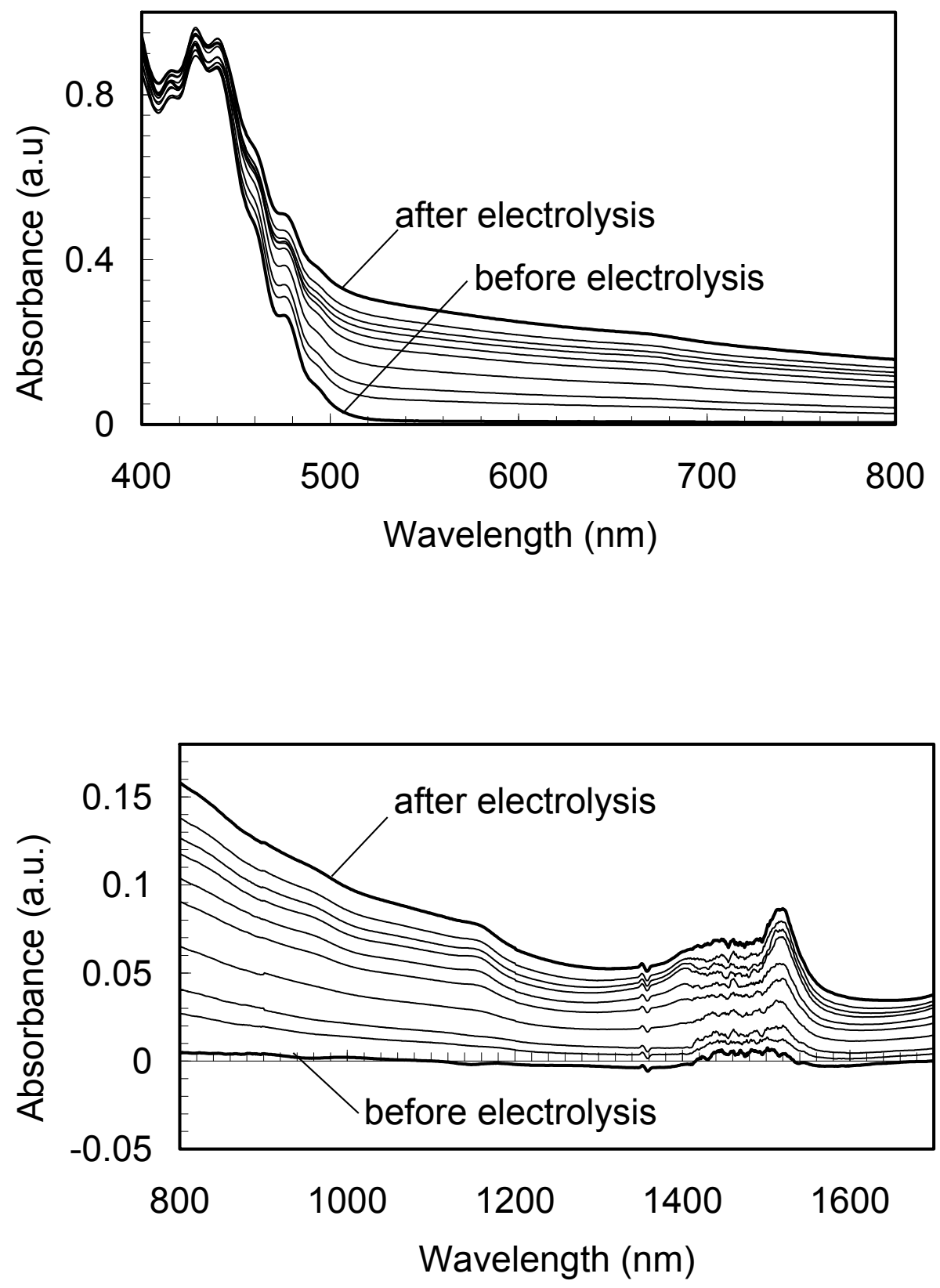

Fig. 9, Uehara, et al., 


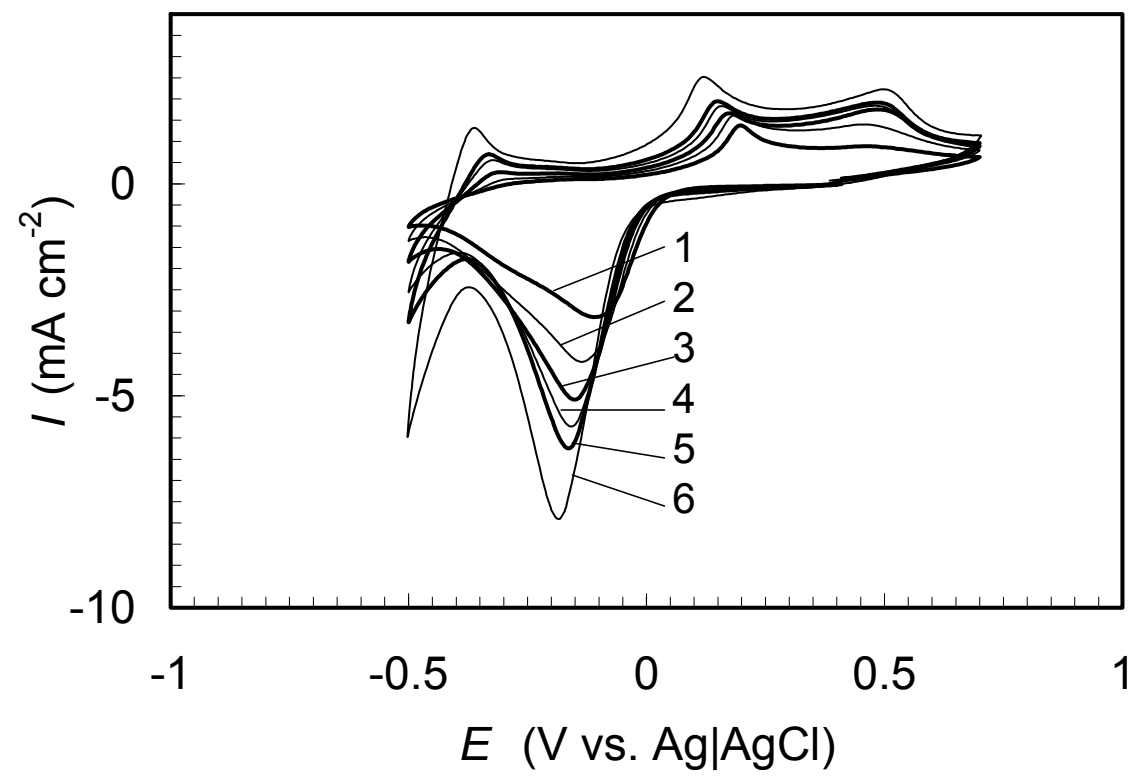

Fig. 10, Uehara, et al., 